\title{
Adding attractive semio-chemical trait refines the taxono- my of Alpinobombus (Hymenoptera: Apidae)
}

\author{
Baptiste Martinet ${ }^{1}$, Nicolas Brasero ${ }^{1}$, Thomas LecocQ ${ }^{1,2}$, Paolo Biella ${ }^{3,4}$, \\ Irena Valteroví ${ }^{5}$, Denis Michez ${ }^{1}$, Pierre Rasmont ${ }^{1}$ \\ ${ }^{1}$ University of Mons, Research Institute of Biosciences, Laboratory of Zoology, Place du Parc 20, 7000, Mons, Belgium \\ ${ }^{2}$ Research Unit Animal and Functionalities of Animal Products (URAFPA), University of Lorraine - INRA, 2 Avenue de \\ la Forêt de Haye, BP 172, 54505, Vandoeuvre-lès-Nancy, France \\ ${ }^{3}$ Department of Zoology, Faculty of Science, University of South Bohemia, Branišovská 31, 37005, České Budějovice, \\ Czech Republic \\ ${ }^{4}$ Biology Centre, Institute of Entomology, Czech Academy of Sciences, Branišovská 31, 37005, České Budějovice, \\ Czech Republic \\ ${ }^{5}$ Institute of Organic Chemistry and Biochemistry, Academy of Sciences of the Czech Republic, Flemingovo nám 2, CZ- \\ 166 10, Prague, Czech Republic
}

Received 2 February 2018 - Revised 10 July 2018 - Accepted 4 October 2018

\begin{abstract}
Species taxonomy of bumblebees (Bombus Latreille, 1802) is well known to be problematic due to a potentially high intra-specific variability of morphological traits while different species can converge locally to the same color pattern (cryptic species). Assessing species delimitation remains challenging because it requires to arbitrarily select variable traits whose accuracy continues to be debated. Integrative taxonomic approach seems to be very useful for this group as different independent traits are assessed to propose a rational taxonomic hypothesis. Among operational criteria to assess specific status, the reproductive traits involved in the pre-mating recognition (i.e., the male cephalic labial gland secretions, CLGS) have been premium information. Since these secretions are supposed to be species-specific, these chemical traits can bring essential information where species delimitation is debated. Here, we describe and compare the CLGS of 161 male specimens of nine Alpinobombus taxa: alpinus, balteatus, helleri, hyperboreus, kirbiellus, natvigi, neoboreus, polaris, and pyrrhopygus. We aim also to test the congruence between this new information (reproductive traits) and published genetic dataset. Our results emphasized six distinct groups with diagnostic major compounds: (a) alpinus + helleri with hexadec-9-en-1-ol; (b) polaris + pyrrhopygus with two major compounds hexadec-9-en-1-ol and hexadec-9-enal; (c) balteatus with tetradecyl acetate; (d) kirbiellus with geranyl geranyl acetate; (e) hyperboreus + natvigi with octadec-11en-1-ol; (f) neoboreus with octadec-9-en-1-ol. Based on this new information, we can confirm the species status of B. alpinus, B. balteatus, B. hyperboreus, B. kirbiellus, B. neoboreus, and B. polaris. We also confirm the synonymy of helleri (Alps) with alpinus (Sweden). However, the specific status of natvigi (Alaska) and pyrrhopygus (Sweden) is questionable and these taxa do not have specific CLGS composition.
\end{abstract}

\section{bumblebees / species / cephalic labial gland secretions / arcto-alpine distribution / chemical trait}

\section{INTRODUCTION}

Electronic supplementary material The online version of this article (https://doi.org/10.1007/s13592-018-0611-1) contains supplementary material, which is available to authorized users.

Corresponding author: B. Martinet, baptiste.martinet@umons.ac.be

Manuscript editor : Marina Meixner
The bumblebees (Bombus Latreille, 1802) are eusocial insects widely distributed and included 250 species over the world (reviewed in Williams et al. 2008). Their diversity hotspots are localized in cold and temperate regions (Pekkarinen et al., 1981; Heinrich 2005). They have been studied for 
a long time by many entomologists because of their large size, attractive coat color pattern, and their economic value as crop pollinators (Michener, 2007; Klein et al. 2007; Patiny et al. 2009; Goulson 2010).

The subgenus Alpinobombus (Skorikov, 1914) is a small monophyletic subgenus particularly adapted (i.e., heterothermic thermo-regulation system) and restricted to the coldest areas of the bumblebee distribution such as Alaska, Fennoscandia, N. Siberia, or Greenland (Skorikov 1914; Milliron and Olivier, 1966; Løken 1973; Richards 1973; Heinrich 2005; Berezin 1995). Their presence is crucial for biodiversity and conservation of mountain and tundra habitats (Richards 1973) especially for pollination of arctic wild plants (e.g., Astragalus spp., Bartsia spp., Hedysarum spp., Pedicularis spp., Salix spp., Vaccinium spp.) (Shamurin, 1966; Kevan 1973; Løken 1973; Richards 1973; Stenström \& Bergman 1998; Taylor \& Rumsey 2003; Eriksen et al. 2006; Biella et al. 2017). Recent studies showed that some of these arctoalpine populations are in decline and most likely because climate change (Martinet et al. 2015; Rasmont et al. 2015).

Conservation of a species group and its ecosystem service requires theoretical knowledge about its biology, ecology, and systematics. The Alpinobombus subgenus has been the focus of systematic studies using morphological characters (e.g., color pattern) that have since been highly criticized (Bickford et al. 2007; Batalha-Filho et al. 2010; Carolan et al. 2012; Lecocq et al. 2015). Indeed, due to their morphological similarities and their circum-polar distribution (i.e., isolated populations with relict populations in southern mountain ranges), many different taxa could show doubtful taxonomic status (Løken 1973; Williams et al. 2015). Several authors have examined the species of Alpinobombus, but no consensus on the number of valid species could be found (Richards 1931; Skorikov 1914; Løken 1973; Milliron 1973). Acknowledging the need of taxonomic revision, a recent study has used a more accurate trait than only morphological diagnose: DNA markers (Williams et al. 2015). Williams et al. (2015) proposed the hypothesis of nine putative species and one unnamed species, later described as B. kluanensis Williams et al., 2016based on genetic barcode and morphology: B. alpinus Linnaeus, 1758; B. balteatus Dahlbom, 1832; B. hyperboreus Schönherr, 1809; B. kirbiellus Curtis, 1835; B. kluanensis Williams et al., 2016; B. natvigi Richards, 1931; B. neoboreus Sladen, 1919; B. polaris Curtis, 1835; and B. pyrrhopygus Friese, 1902 (Figure 1). In addition to the description of the new species B. kluanensis (Canada), the nomenclatural operations consisted of splitting the taxon hyperboreus into B. hyperboreus (Scandinavia and far East Siberia) and B. natvigi (Canada, Alaska), the taxon polaris into $B$. polaris (Alaska, Canada, Greenland) and B. pyrrhopygus (Scandinavia, Russia), and the taxon balteatus (Scandinavia, Russia, Mongolia) into B. balteatus and B. kirbiellus (USA including Alaska, Canada). However, defining the species threshold in DNA barcoding analyses remains challenging despite the development of new statistical techniques such as Bayesian implementation of the general mixed Yule-coalescent model (bGMYC) to recognize species threshold (Pons et al. 2006; Andriollo et al. 2015; Lecocq et al. 2015; Mutanen et al. 2016). This issue can be overcome by integrating the DNA investigations with other pieces of evidence of speciation such as attractive semio-chemical traits or morphology in an integrative framework.

The bumblebee systematic remains challenging (Bertsch \& Schweer 2012; Lecocq et al. 2015; Williams et al. 2012; Potapov et al., 2018). Development of an integrative taxonomy approach based on consensus between several independent traits (i.e., DNA, eco-chemical traits) provides an efficient solution to refine bumblebee systematic (Engel 2011; Lecocq et al. 2015). The congruence between independent traits can support the reliability of taxonomic conclusions (de Queiroz 2007). Indeed, although a differentiation in one character can be enough to highlight speciation process (Schlick-Steiner et al. 2010), the species status should be supported only if it is suggested by several lines of evidence. Therefore, the safest way is a strict approach where a taxon deserving a species status is a taxon with differentiation in all studied traits (Lecocq et al. 2015). 

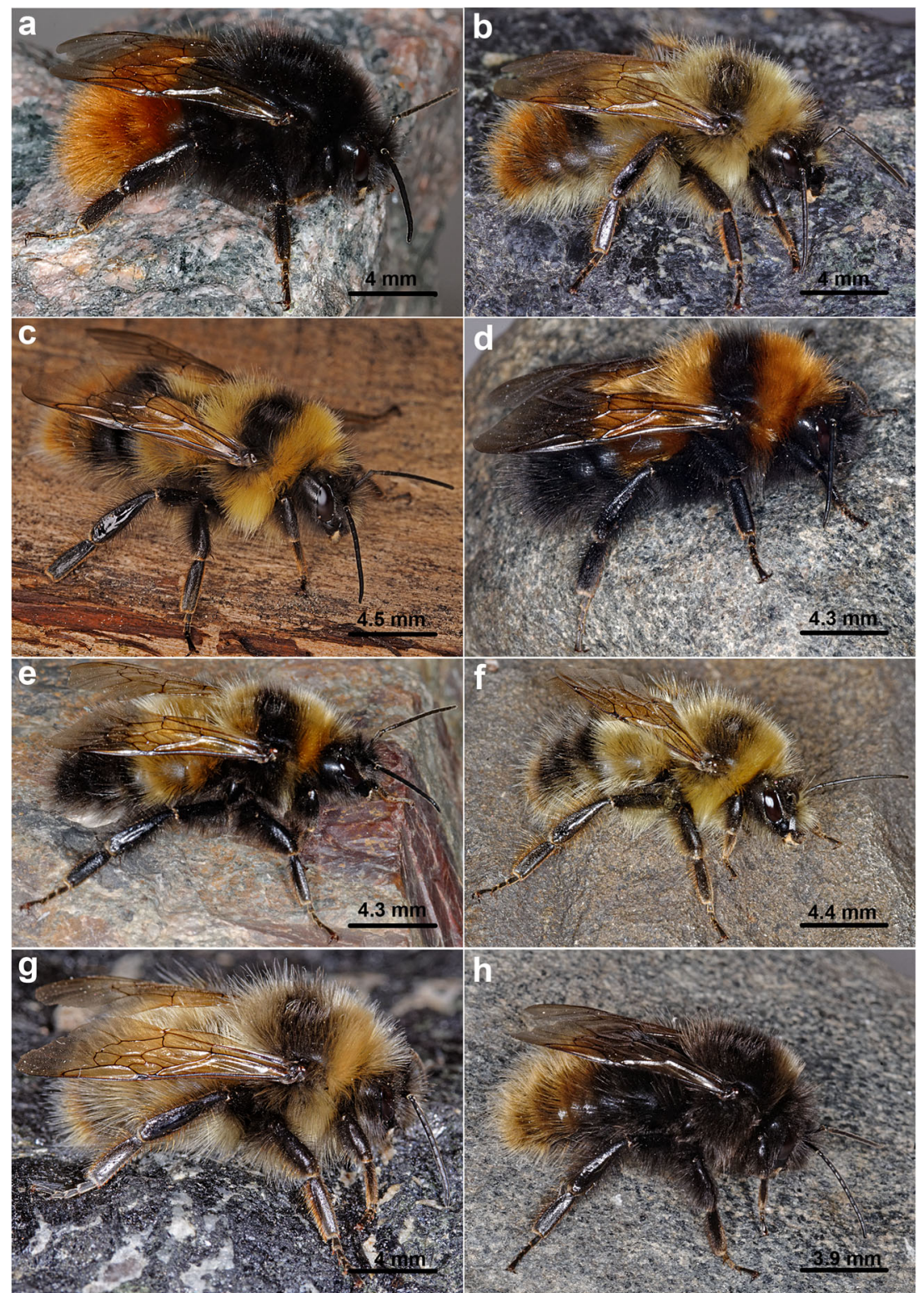

Figure 1 Pictures of eight studied Alpinobombus taxa. a Bombus alpinus male PRAS0806 from Sweden. b B. kirbiellus male PRAS1409 from Yukon (Canada). c B. balteatus male PRAS1653 from Khanymei (Siberia). d B. hyperboreus male BMAR0054 from Sweden. e B. natvigi male PRAS1067 from Alaska. f B. polaris male PRAS1040 from Alaska. g B. neoboreus male PRAS1435 from Yukon (Canada). h B. pyrrhopygus male PRAS0929 from Norway (All Photos by P. Rasmont).

Several authors used operational criteria in bumblebee taxonomy such as genetic or semiochemical traits (i.e., cephalic labial gland secretions; CLGS) (e.g., Junior et al. 2015; Lecocq et al. 2015; Martinet et al. 2018). The bumblebee pre-mating recognition system involves CLGS as attractive compounds for virgin females during nuptial behavior (i.e., "route-flight" or patrolling 
behavior) (Ayasse \& Jarau 2014). CLGSs are synthesized de novo (Žacek et al., 2013) and consist of a complex mixture of mainly aliphatic compounds (Coppée et al. 2008). Semio-chemical traits are shaped by selective pressure to allow the meeting of conspecific sexual partners and minimize heterospecific hybridization (Paterson 1993; Symonds et al. 2009; Wyatt 2003). Several studies showed that these semio-chemical compounds are highly species-specific (Bergström and Svensson 1973; Svensson 1980; Baer 2003; Bertsch \& Schweer 2012; Ayasse \& Jarau 2014; Lecocq et al. 2015). Despite the usefulness as chemotaxonomic characters of CLGS in bumblebee taxonomy, the CLGS composition of Alpinobombus taxa is only known roughly from Scandinavia and it has been studied with less accurate techniques (Svensson and Bergström, 1979). CLGS are significantly differentiated when we have (a) specific major compounds (abundant relative concentration $>5 \%$ ), (b) specific indicator compounds, and (c) significative statistical differentiation test (high bootstrap values clustering and differentiation in multivariate statistic test) (Martinet et al. 2018).

Here, we propose to compare the DNA-based taxonomic conclusions on Alpinobombus to CLGS differentiation pattern in order to confirm or to reassess the taxonomic conclusions proposed by Williams et al. (2015).

\section{MATERIALS AND METHODS}

\subsection{Sampling}

A total of 161 alive bumblebee males collected between 2013 and 2017 were analyzed (Tab. S1). We were able to sample $B$. alpinus $(n=15)$ from Fennoscandia, B. alpinus helleri $(n=5)$ from Alps (Italy), $B$. polaris $(n=21)$ from Alaska, B. pyrrhopygus $(n=3)$ from Fennoscandia, $B$. balteatus from Sweden $(n=19)$ and from Siberia $(n=20), B$. natvigi from Alaska $(n=8)$, B. hyperboreus from Fennoscandia $(n=7)$, $B$. neoboreus from Alaska $(n=19)$ and Yukon $(n=)$, and B. kirbiellus from Alaska $(n=20)$ and from Yukon $(n=16)$ (Figure 1). Despite efforts to find B. kluanensis specimens in its species original location (locus typicus, Kluane lake, Yukon), we have not been able to collect it. The individual bumblebee specimens were killed by freezing at $-20{ }^{\circ} \mathrm{C}$. The field work was performed at Abisko (Sweden), Alps (Italy), Khanymey (W-Siberia), Kluane lake (Yukon, Canada), and Toolik field station (Alaska) (Figure 2).

\subsection{Reproductive trait description}

We focused on the most studied reproductive trait involved in the bumblebee pre-mating recognition (Svensson 1980; Ayasse \& Jarau 2014; Baer 2003; Lecocq et al. 2015): the cephalic labial gland secretions (CLGS). CLGS were extracted with $400 \mu$ of $n$-hexane (De Meulemeester et al. 2011). Samples were stored at $-40{ }^{\circ} \mathrm{C}$ prior to the analyses. All samples have been extracted just after collection day to avoid alteration bias. Cephalic labial gland secretions have been analyzed on the same year to ensure a good conservation of samples and to avoid analytical bias.

The qualitative composition of the CLGS was determined by gas chromatography mass spectrometry using a Finigan GCQ quadrupol system (GC/MS) with a non-polar DB-5 ms capillary column [5\% phenyl (methyl) polysiloxane stationary phase; column length $30 \mathrm{~m}$; inner diameter $0.25 \mathrm{~mm}$; film thickness $0.25 \mu \mathrm{m}]$. Double bound positions $(\mathrm{C}=\mathrm{C})$ were determined by dimethyl disulfide (DMDS) derivatization (Vincenti et al. 1987). All samples were quantified with a gas chromatograph Shimadzu GC-2010 system (GCFID) equipped with a non-polar SLB-5 ms capillary column [5\% phenyl (methyl) polysiloxane stationary phase; column length $30 \mathrm{~m}$; inner diameter $0.25 \mathrm{~mm}$; film thickness $0.25 \mu \mathrm{m}$ ] and a flame ionization detector. All compounds for which relative abundance (RA) were recorded as less than $0.1 \%$ for all specimens were excluded from the analysis (De Meulemeester et al. 2011). The data matrix for each taxa was based (Appendix S2) on the alignment of each relative proportion of compound between all samples performed with GCAligner 1.0 (Dellicour \& Lecocq $2013 \mathrm{a}$, b). We defined "main compounds" as compounds that have the highest relative proportion (RA) among all compounds of CLGSs profile of at least one individual of the taxon. To facilitate the alignment of compounds and their identification, before each sample injection, a mixture of 


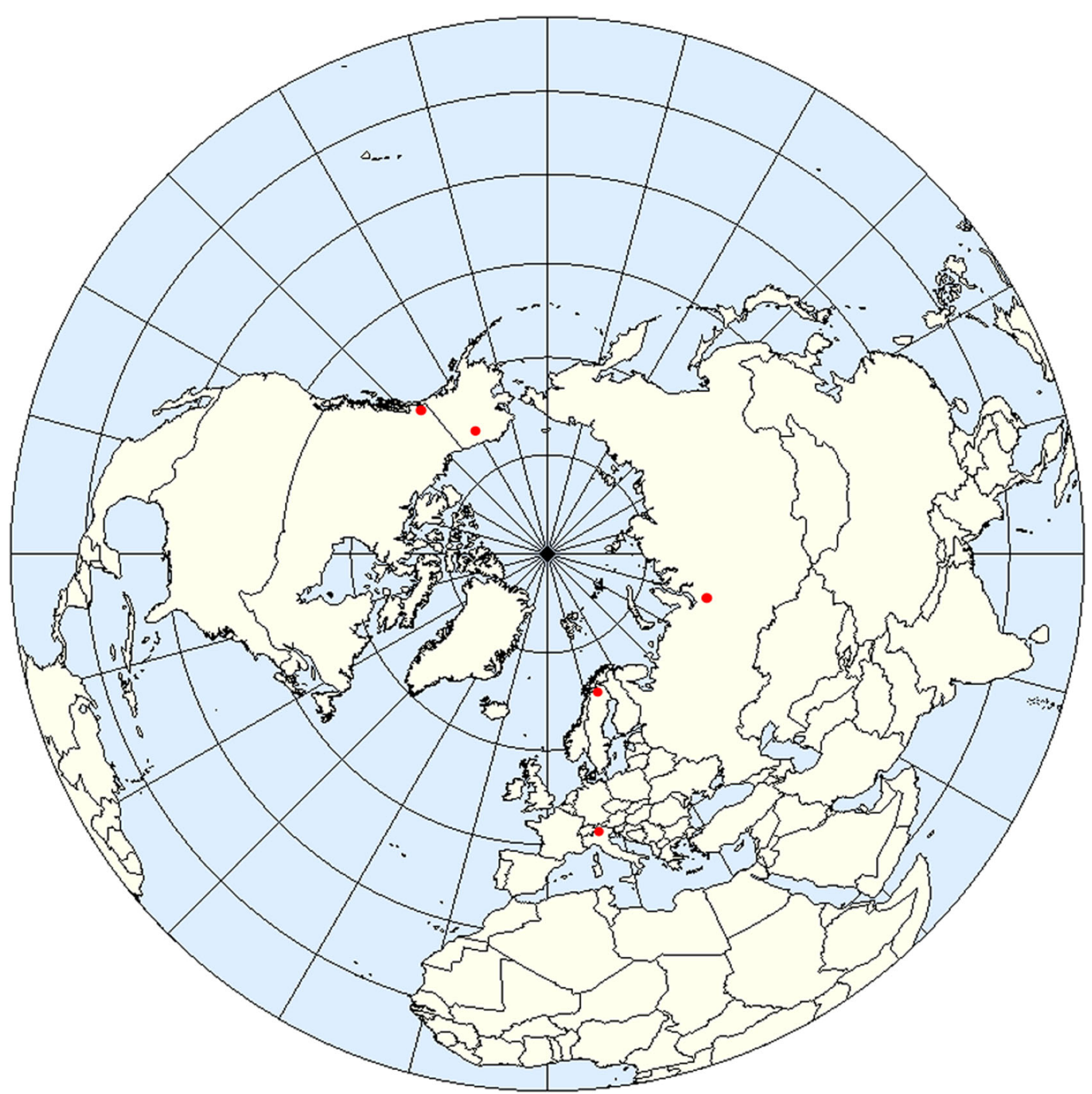

Figure 2 Circum arctic sampling map (Northern Hemisphere polar Lambert Azimutal projection) after original of Sean Baker on which the red dots indicate the areas where we collected specimens of Alpinobombus.

alkanes C10-C40 was injected as a standard for calculation Kovats indices (KI). KI were calculated with GC Kovats 1.0 according to the method described by Dellicour \& Lecocq (2013).

\subsection{Statistical analysis}

We performed statistical comparative analyses of the CLGSs using R (R Development Core Team 2017) to detect CLGS differentiations between Alpinobombus taxa. To detect divergence in CLGS composition, we performed a principal component analysis (PCA) based on correlation distance matrix, and a clustering method, computed with the unweighted pair-group method with average linkage (UPGMA) based on Pearson Phi correlation distance matrix ( $\mathrm{R}$ package ape; Paradis et al. 2004). We assessed the uncertainty in hierarchical cluster analysis using $p$ values calculated via multiscale bootstrap resampling with 100,000 bootstrap replications (R package pvclust, Suzuki \& Shimodaira 2011). When we observed a 
differentiation in our clustering and PCA analyses, we checked CLGS differentiations between taxa by performing a permutational multivariate analysis of variance (perMANOVA) followed by pairwise perMANOVA using the Bray-Curtis dissimilarity matrix (R package vegan, Oksanen et al. 2017). Prior to these tests, the multivariate homogeneity of within-group covariance matrices was verified using the "betadisper" function. When a significant difference was detected, we performed multiple pairwise comparisons with an adjustment of $p$ values (Bonferroni correction). To determine specific compounds of each taxon (indicator compounds, IC, $p$ value $>0.70$ ), the indicator-value (IndVal) method was used (Claudet et al. 2006; Dufrene and Legendre, 1997). The statistical significance of indicator compounds (threshold of 0.01) was evaluated with a randomization procedure.

\section{RESULTS}

\subsection{Composition of cephalic labial gland secretions}

Overall, within the CLGS, our analyses allowed the detection of 155 compounds: 51 from B. alpinus and 51 from B. alpinus helleri [IC alpinus /helleri = 5], 66 from B. polaris, 64 from B. pyrrhopygus [IC polaris/pyrrhopygus $=11$ ], 66 from $B$. balteatus [IC =18], 63 from $B$. kirbiellus [ $\mathrm{IC}=12], 63$ from $B$. hyperboreus, 66 from $B$. natvigi [IC hyperboreus/natvigi $=22$ ], and 64 from $B$. neoboreus [IC = 13] (Appendix $\mathrm{S} 2$ ). Several minor compounds were shared by all Alpinobombus taxa such as octadecenoic acid, tricos-9-ene, pentacosane, heptacos-9-ene, heptacosane, nonacos-9-ene, nonacosane, and hentriacontene. Several other compounds were detected in large amounts (median $>5 \%$ ) with Alpinobombus taxa: (i) hexadec-9-en-1-ol $(64.32-89.43 \%)$ in alpinus; (ii) hexadec-9-enal $(0.62-10.86 \%)$ in helleri; (iii) dodecyl butyrate (3.51-30.47\%), tetradecyl butyrate (8.16$28.89 \%$ ), geranyl citronellol (2.68-27.01\%) in balteatus; (iv) octadecenoic acid (1.84-20.54\%) in kirbiellus; (v) dihydrofarnesol (12.29$23.41 \%)$, geranyl citronellol $(2.87-7.00 \%)$ in hyperboreus ; (vi) dihydrofarnesol (9.05$18.13 \%)$, octadecenoic acid (4.59-10.09\%), geranyl citronellol $(4.18-12.42 \%)$ in natvigi; (vii) tetradec-9-en-1-ol (6.58-29.97\%), octadecenoic acid (1.19-14.23\%), sitosterol $(0.40-11.06 \%)$ in neoboreus ; (viii) hexadecenoic acid (3.80-13.62\%), octadecenoic acid (2.87$16.20 \%$ ), hexadecenyl hexadecenoate (3.63$20.74 \%$ ) in polaris; (ix) hexadecenyl hexadecenoate $(4.56-6.47 \%)$ in pyrrhopygus . The full list of identified compounds is presented in Supplementary file 2.

Our hierarchical analyses and principal component analysis (ACP, data matrix of 155 compounds $\times 161$ specimens) emphasized six distinct groups with specific main compounds (Table I) supported by high multiscale bootstrap resampling values (Figure 3): (i) B. alpinus + B. alpinus helleri with hexadec-9-en-1-ol (64.32-89.43\%) which largely dominate the volatile marking secretion; (ii) B. polaris + B. pyrrhopygus with hexadec-9-en-1-ol (7.78-43.17\%) and hexadec9-enal $(9.62-46.52 \%)$; (iii) B. balteatus with tetradecyl acetate (13.17-47.17\%); (iv) $B$. kirbiellus with geranyl geranyl acetate (28.50-80.59\%); (v) B. hyperboreus + $B$. natvigi with octadec-11-en-1-ol (23.90$56.80 \%$ ); (vi) B. neoboreus with octadec-9-en-1ol $(25.59-58.11 \%)$. The specific recognition signals differed significantly among groups, providing a good indication on the specific status of these taxa. While the typical chromatograms (chemical fingerprint) of these groups were unique, we observed similarities in the spectrum profile between $B$. alpinus and $B$. polaris and between $B$. hyperboreus and $B$. neoboreus. The variability of compound profiles was low for each taxa except for B. alpinus helleri showing different relative abundance of hexadec-9-enal ( $\mathrm{min}$ $0.62 \%-\max 10.86 \%$ ).

Several significant and specific indicator compounds were revealed by the IndVal method (IndVal >0.70) (Appendix S2): (a) alpinus + helleri (IC = 5), (b) polaris + pyrrhopygus ( $\mathrm{IC}=11)$, (c) balteatus ( $\mathrm{IC}=18)$, (d) kirbiellus $(\mathrm{IC}=12),(\mathrm{e})$ hyperboreus + natvigi ( $\mathrm{IC}=22)$, (f) neoboreus $(\mathrm{IC}=13)$. Hexadecenyl hexadecanoate $(0.22-$ $1.10 \%)$ and geranyl citronellyl tetradecanoate $(0.07-0.43 \%)$ were detected in B. natvigi but not in $B$. hyperboreus . Moreover, several compounds such as octadecenoic acid were detected only in 


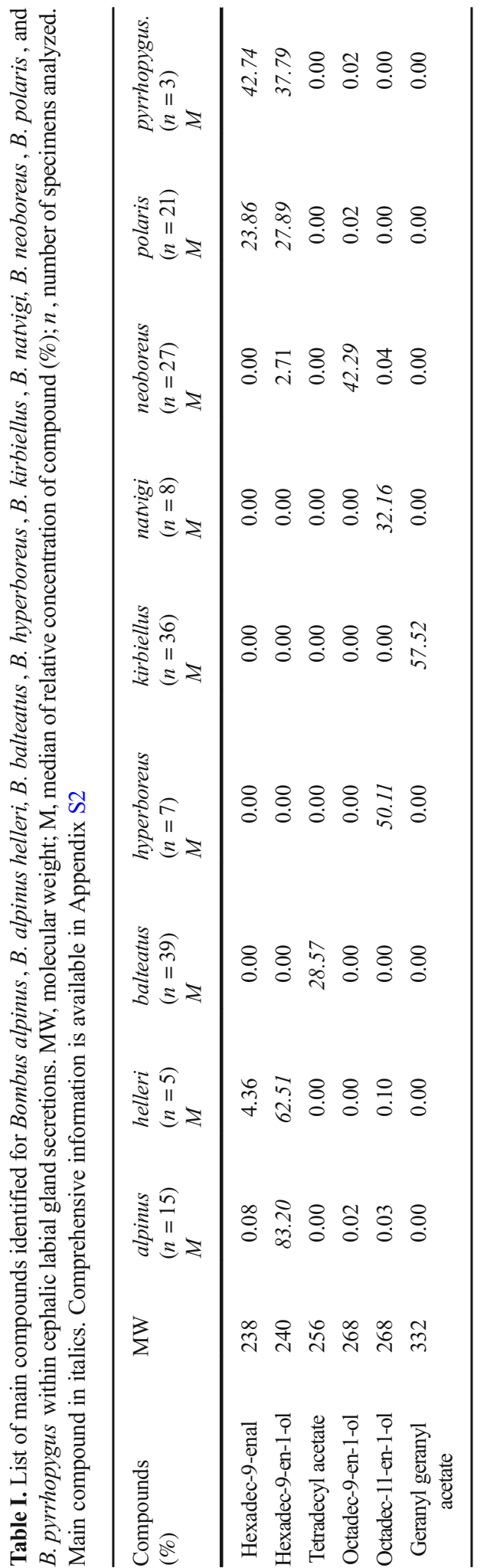

small amounts in natvigi $(0.05-3.94 \%)$ and in larger amounts in B. hyperboreus (4.59-10.09\%). Concerning B. alpinus/helleri, hexadecanoic acid (0.15-2.02\%), ethyl octadec-11-enoate (0.04$1.09 \%)$, and X9 $(0.10-0.40 \%)$ were detected in helleri but not in B. alpinus and sitosterol $(0.00$ $0.70 \%$ ) was detected in B. alpinus but not in B. alpinus helleri .

Statistical test (perMANOVA) confirmed that "taxa factor" has a significant effect on CLGS composition $\left(F_{8,152}=209.76, p<0.001\right)$. Significant differences have been found between balteatus and kirbiellus (pairwise perMANOVA $\left.F_{1,73}=46.277, p<0.001\right)$, balteatus and hyperboreus /natvigi $\left(F_{1,52}=188.39, p<0.001\right)$, balteatus and alpinus/helleri $\left(F_{1,58}=328.52\right.$, $p<0.001)$, balteatus and polaris/pyrrhopygus $\left(F_{1,61}=273.26, p<0.001\right)$, balteatus and neoboreus $\left(F_{1,64}=59.77, p<0.001\right)$, neoboreus and hyperboreus/natvigi $\left(F_{1,40}=247.91\right.$, $p<0.001)$, neoboreus and alpinus/helleri $\left(F_{1,46}=383.82, p<0.001\right)$, neoboreus and polaris /pyrrhopygus $\left(F_{1,49}=263.66, p<0.001\right)$, neoboreus and kirbiellus $\left(F_{1,61}=418.67\right.$, $p<0.001)$, kirbiellus and alpinus/helleri $\left(F_{1,54}=382.16, p<0.001\right)$, kirbiellus and polaris /pyrrhopygus $\left(F_{1,58}=268.37, p<0.001\right)$, kirbiellus and hyperboreus/natvigi $\left(F_{1,49}=\right.$ 234.44, $p<0.001)$, alpinus /helleri and polaris / pyrrhopygus $\left(F_{1,42}=93.44, p<0.001\right)$, alpinus $/$ helleri and hyperboreus/natvigi $\left(F_{1,33}=256.79\right.$, $p<0.001$ ), and between hyperboreus/natvigi and polaris /pyrrhopygus $\left(F_{1,37}=159.06, p<0.001\right)$.

\section{DISCUSSION}

For a long time, so-called cryptic species have caused problems for bumblebee taxonomy (Carolan et al. 2012; Williams et al. 2012). Indeed, the lack of separating morphological characteristics was a significant impediment. Although coat coloration is useful for quick and efficient identification of bumblebees in the field (in addition to other structural criteria), critical errors could occur (Bertsch \& Schweer, 2011). Within Alpinobombus taxa, the problem is that reliable species-specific morphological differences are slight (Williams et al. 2015). In this case, integrating genetic markers, CLGS, and other operational 

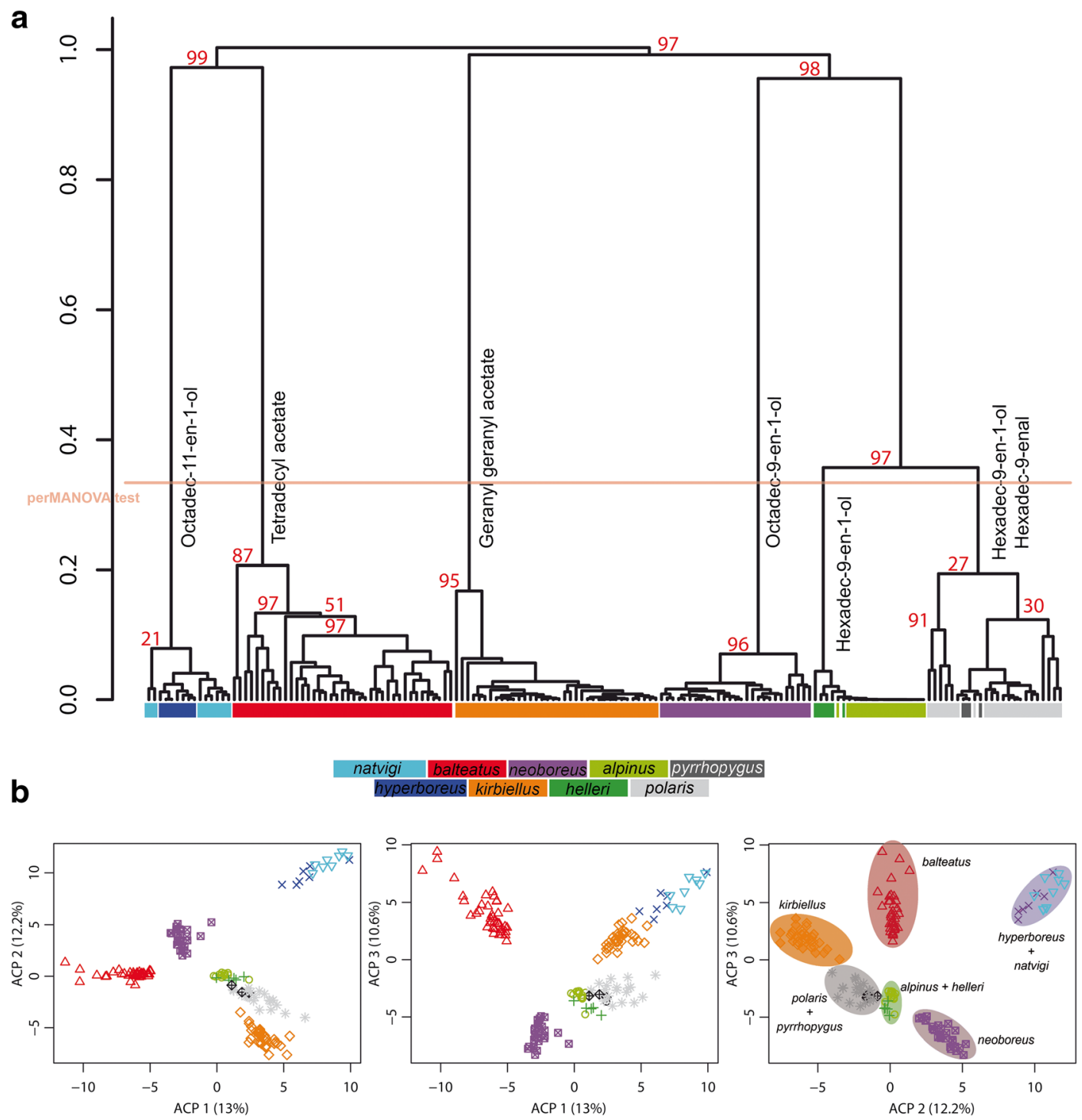

Figure 3 a Dendrogram based on cephalic labial gland secretions of Bombus alpinus, B. alpinus helleri, $B$. balteatus, B. hyperboreus, B. kirbiellus, B. natvigi, B. neoboreus, B. polaris, and B. pyrrhopygus. This cluster was obtained by hierarchical clustering using an unweighted pair-group method with arithmetic mean (UPGMA) based on a correlation matrix. The values near nodes represent multiscale bootstrap resampling values. The main compound of each taxa has been annotated on the main branches of the cluster. b Principal component analysis (PCA) of cephalic labial gland secretion differentiation on 155 compounds $\times 161$ specimens within Alpinobombus taxa: Bombus alpinus, B. alpinus helleri, B. balteatus, B. hyperboreus, B. kirbiellus, B. natvigi, B. neoboreus, B. polaris , B. pyrrhopygus . PC1, PC2, and PC3 are the first, the second, and the third principal component axes.

taxonomic criteria in an integrative framework could bring useful information for biochemical systematics for separation of critical taxa in the context of species delimitation according to an integrative approach sensu de Queiroz (2007).
Nuptial behavior and scent marking of bumblebees have been the subject of several studies (see review in Ayasse \& Jarau 2014). For the Alpinobombus, Svensson \& Bergström (1979) described the patrolling behavior of B. alpinus, 
B. polaris, B. balteatus, and B. hyperboreus during their courtship which involved a deposit of long-distance attractive substances on different substrates. Svensson \& Bergström (1979) suggested that these CLGS are sex pheromones and are involved in attracting virgin females during patrolling behavior. The gland secretions analyzed in the present study contained the common mixtures of aliphatic compounds and straight-chain fatty acid derivatives (alcohols, esters, aldehydes, and hydrocarbons) already detected in the CLGS of the subgenus Alpinobombus (Svensson \& Bergstrom 1979).

\subsection{Description of the CLGS of Bombus kirbiellus}

We found a unique CLGS mixture dominated by geranylgeranyl acetate for Bombus kirbiellus (North America), very different from its sister species Bombus balteatus (Eurasia) dominated by tetradecyl acetate. Our investigation of CLGS of kirbiellus (North America) confirms the results of genetic analysis performed by Williams et al. (2015) (Figure 3). As discussed in Brasero et al. (2015), the geranylgeranyl acetate is also the main compounds identified in Cullumanobombus species (Hovorka et al. 2006), in $B$. (Alpigenobombus) wurflenii (Svensson et al. 1984) and B. (Kallobombus) soroeensis (Kullenberg et al. 1970). In other insects, Symonds \& Elgar (2004) suggested that most chemical components were distributed randomly across the phylogeny in bark beetles (Dendroctonus ). Our results confirm that the same main compound could be shared by different species phylogenetically and in this case geographically distant.

\subsection{Differentiation of helleri/alpinus, hyperboreus/natvigi, and polaris and pyrrhopygus}

In their recent taxonomic revision, Williams et al. (2015) suggested that (i) populations of alpinus from Alps (also called subspecies helleri) and N. Scandinavia (alpinus) are conspecific, (ii) the heterospecificity between natvigi (North America) and hyperboreus (Scandinavia, Russia), and the heterospecificity between polaris
(Alaska, Canada, Greenland) and pyrrhopygus (Sweden, Russia) based on COI and PEPCK gene fragments.

Concerning alpinus/helleri, based on CLGS matrix, hierarchical and principal component analyses showed only one group mixing the two populations (Figure 3). However, minor quantitative differences (e.g., variability of the relative abundance of the hexadec-9-enal in helleri) can be observed in the spectrum. For hyperboreus / natvigi, hierarchical and principal component analyses showed also only one group gathering the two taxa (Figure 2). For these taxa, we observed quantitative differences involving very minor compounds (median $<0.20 \%$ ) close to our threshold of $0.1 \%$ which have probably not a major role in pre-mating recognition (Appendix S2). Brasero et al. (2017) and Terzo et al. (2005) showed intraspecific variability in the CLGS of different bumblebee species. Several compounds could be abundant or absent according to the specimen analyzed. Several authors have shown that CLGS composition may change during the lifetime of the male (age-dependent; Žáček et al. 2009) and even during the day (more active in the morning) (Bergman 1997). However, as discussed by Bertsch \& Schweer (2011), these parameters do not modify significantly the species-specific chemical fingerprint. Following our CLGS divergence threshold, we suggest to consider these differences as random intra-specific variability explained by geographical isolation (Coppée et al. 2008; Martinet et al. 2018). We confirmed therefore the hypothesis of Williams et al. (2015) for the taxa helleri/alpinus but not for the taxa hyperboreus/natvigi.

As for hyperboreus/natvigi, the results of CLGS of polaris (Alaska) and pyrrhopygus (Scandinavia) do not confirm the recent taxonomic hypothesis of Williams et al. (2015) based on genetic analysis (Figure 3). Indeed, hierarchical and principal component analyses emphasize a unique group. Despite the coat color differentiation, all studied specimens seem to belong to the same species, B. polaris. As suggested by Martinet et al. (2018), mate recognition system is speciesspecific and differ even between closely related bumblebee species which have geographical distributions that do not overlap. Moreover, inside these three taxa pairs (alpinus/helleri; hyperboreus / 
natvigi; polaris /pyrrhopygus ), none difference involving main compounds have been observed contrary to what has been observed in the pairs B. balteatus/B. kirbiellus and B. hyperboreus/ $B$. neoboreus (closely related species, Williams et al. 2015). However, Symonds et al. (2009) and Symonds \& Elgar (2007) suggested in other insect groups that at speciation event, pheromones differ via large shifts in composition (involving abundant compounds) by saltational changes even where other mechanisms exist to ensure reproductive isolation (e.g., allopatry). Subsequently, gradual changes also occur to differentiate taxa (Symonds et al. 2009). Main compounds have been suggested to be strong indicator of potential ethological consequences for pre-mating recognition (Lecocq et al. 2015). However, in bumblebees, several studies have shown that uncontestable different species (e.g., Cullamanobombus Brasero et al. 2015; Hovorka et al. 2006; Bombus muscorum and Bombus filchnerae Brasero et al. 2017) have the same main compounds. This could indicate that minor compounds could play also a key role in bumblebee species discrimination as diagnostic character. However, further ethological tests or neural coding studies (e.g., electrophysiological recordings) are needed to assess the role of these minor compounds as neural stimuli in the context of nuptial behavior.

In their taxonomic revision, Williams et al. (2015) have showed that nuclear gene (phosphoenolpyruvate carboxykinase) did not allow to differentiate the ambiguous taxa polaris/ pyrrhopygus and natvigi/hyperboreus (no unique haplotype). Nevertheless, these couples of taxa were significantly divergent in mitochondrial gene (cytochrome oxidase 1) with bGMYC threshold (Williams et al. 2015). However, recent studies highlighted the high variability of this gene (COI) at intra- and interspecific levels and questioned the COI-based taxonomic conclusions in the absence of corroborations by other taxonomic criteria (e.g., Trunz et al. 2016; Soltani et al. 2017). From a morphological point of view, COIbased taxonomic statuses are not corroborated: there are very few differences between polaris and pyrrhopygus or between natvigi and hyperboreus except a slight color pattern differentiation (Williams et al. 2015). However, color pattern was shown to be a poor taxonomic criterion in bumblebees, making the differentiation doubtful (Bickford et al. 2007; Batalha-Filho et al. 2010; Carolan et al. 2012; Lecocq et al. 2015). Similarly, our CLGS-based conclusions (reproductive traits involved in the pre-mating recognition system) are divergent from COI-based previous study. A hypothesis to explain this divergence could be that these taxa are in a speciation process and that these two data types have different evolution rates (e.g., Symonds et al. 2009). Indeed, according to the species delimitation criterion system used, we assign or not the species status to these allopatric populations, hence the importance to integrate these criteria into an integrative framework to refine our taxonomic hypothesis (higher specificity). Therefore, we advocate to use a more complete integrative taxonomic approach (see such a strict method in Lecocq et al. 2015; Martinet et al. 2018) considering here all available independent operational criteria (genetic, morphological, CLGS datasets) to propose a more supported taxonomic hypothesis. Following this integrative approach, pyrrhopygus should be considered as conspecific with polaris and natvigi conspecific with hyperboreus .

When comparing different datasets, involving independent traits commonly used in bumblebee systematic, such as morphology (Williams et al. 2015), genetic (Williams et al. 2015), and chemical (CLGS, present data), it can lead in some cases to an incongruence between different traits in taxonomic conclusions. The integrative taxonomic approach is thus useful for a better supported taxonomic hypothesis. This taxonomic hypothesis depends on the number of criteria used and how to integrate them. Considering that genetic and chemical datasets could have different evolutionary rates (Symonds et al. 2009; Lecocq et al. 2015), it is possible that, according to the criteria used to perform species delimitation, we have or not significant divergence for a taxon involved in a speciation process. Moreover, for the genetic dataset, often only few markers arbitrarily chosen are used (Cruaud et al. 2014). Adding independent operational criteria such as CLGS, which are a very species-specific ecological trait, allow to refine taxonomic hypotheses in an integrative taxonomic approach. 


\subsection{Impact on zoological nomenclature}

When taxa are genetically and chemically differentiated, our analysis support the next nomenclatural situation in Alpinobombus subgenus:

Bombus alpinus (L.,1758) [status confirmed] ssp. alpinus (L.,1758)

ssp. helleri von Dalla Torre, 1882

Bombus balteatus Dahlbom, 1832 [status confirmed]

Bombus hyperboreus Schönherr, 1809

ssp. hyperboreus Schönherr, 1809

ssp. natvigi Richards, 1931 (= Bombus

natvigi Richards 1931, sensu Williams et al. 2015)

Bombus kirbiellus Curtis, 1835 [status confirmed]

Bombus kluanensis Williams et al., 2016[not assessed]

Bombus neoboreus Sladen, 1919 [status confirmed]

Bombus polaris Curtis, 1835

ssp. polaris Curtis, 1835

ssp. pyrrhopygus Friese, 1902 (= Bombus

pyrrhopygus Friese 1902, sensu

Williams et al. 2015)

\subsection{Evolution of CLGS in Alpinobombus}

The variation in the main compound differentiation within Alpinobombus taxa could be due to a switching off and on of specific metabolic pathways (Glaser et al. 2014) and or by activation of an enzyme transcript present in a common ancestor (Roelofs et al., 2002). For instance, between CLGS of $B$. hyperboreus and $B$. neoboreus (two closely related species), the difference in the main compounds lays in the position of the $\mathrm{C}=\mathrm{C}$ double bond (octadec-11-en-1-ol vs octadec-9-en-1-ol). This differentiation may arise by the activity of the enzyme D11-desaturase in B. hyperboreus and D9-desaturase in B. neoboreus (previously described Bombus lucorum by Matoušková et al. (2008), or in other taxa Löfstedt 1993; Brasero et al. 2015). Diagnostic compounds in the male labial gland secretions of many bumblebee species are primary alcohols (Bertsch \& Schweer 2012). Therefore, it is likely that they play a key role in pre-mating recognition (Ayasse \& Jarau. 2014).
Between B. polaris and B. alpinus which share the main compound (hexadec-9-en-1-ol), the CLGS differentiation of the second major compound in $B$. polaris present in equal amount (hexadec-9-enal) and in much lower concentration in B. alpinus could result of a large increase of a minor compound shared by closely related species as suggested by Terzo et al. (2005).

\section{ACKNOWLEDGEMENTS}

The authors thank the Abisko (Sweden), Tarfala (Sweden), Toolik field (USA), Kluane lake (Canada), and Khanymey (W-Siberia) scientific stations for their hospitality and their help in material collection. We acknowledge Hannele Savela (Oulu University, INTERACT administration) for her help in administration process. We thank also K. Urbanová (Institute of Organic Chemistry and Biochemistry ASCR) for her help in chemical analyses. The research leading to these results received funding from the European Union's Horizon 2020 project INTERACT, under grant agreement no. 730938. BM contributes as PhD student granted by the FRS-FNRS (Fonds de la Recherche Scientifique). PB contributes as a PhD student funded by the Czech Science Foundation (GACR GP1410035P) and by the University of South Bohemia (GA JU 152/2016/P). The authors thank the Parco Nazionale dello Stelvio for granting permission to collect in their respective territories to the author $\mathrm{PB}$.

\section{AUTHOR CONTRIBUTION}

Conceived and designed the experiments: BM NB TL PR. Material Collection: BM NB PB PR. Experimentation: BM. Analyzed the data: BM IV. Wrote the paper: BM NB TL PB IV DM PR

L'ajout d'un trait sémio-chimique attractif améliore la taxonomie de l'alpinobombus (hyménoptères: apidés)

Bourdons / espèces / sécrétions des glandes labiales céphaliques / distribution arcto-alpine / caractère chimique.

Die Zusatzinformation bezüglich attraktiver Semiokommunikationsmerkmale verbessert die Taxonomie von Alpinobombus (Hymenoptera: Apidae) 
Hummeln / Arten / Kopflabialdrüsensekrete / arktoalpine Verbreitung / chemisches Merkmal

\section{REFERENCES}

Andriollo T., Naciri Y., Ruedi M. (2015) Two mitochondrial barcodes for one biological species: the case of European Kuhl's Pipistrelles (Chiroptera). Plos One, 10, e0134881.

Ayasse M., Jarau S. (2014) Chemical ecology of bumble bees. Annu. Rev. Entomol. 59, 299-319.

Baer B. (2003) Bumblebees as model organisms to study male sexual selection in social insects. Behav. Ecol. Sociobiol. 54, 521-533.

Batalha-Filho H., Waldschmidt A., Campos L.A.O., Tavares M.G., Fernandes-Salomao T. (2010) Phylogeography and historical demography of the Neotropical stingless bee Melipona quadrifasciata (Hymenoptera, Apidae): incongruence between morphology and mitochondrial DNA. Apidologie, 4, 534 547.

Berezin M.V. (1995) Geographical Diversity, Species Correlation, Population Structure and Cenotic Interactions of Arctic Bumble Bees (Apidae, Bombus ), in: Grönlund E., Melander O. (ed.) Swedish-Russian Tundra Ecology. Expedition-94. Swedish Polar Research Secretariat, Stockholm, pp. 205-215.

Bergman P. (1997) Chemical Communication in Bumblebee Premating Behaviour. PhD thesis, Göteborg University, Sweden.

Bertsch A., Schweer H. (2011) Labial gland marking secretions of male Bombus lucorum bumblebees from Europe and China reveal two separate species: B. lucorum (Linnaeus 1761) and Bombus minshanicola (Bischoff 1936). Biochem.Syst Ecol. 39 (4-6), 587-593.

Bertsch A., Schweer H. (2012) Cephalic labial gland secretions of males as species recognition signals in bumblebees: are there really geographical variations in the secretions of the Bombus terrestris subspecies? Beiträge zur Entomologie, 62, 103-124.

Bergström G., Svensson B.G. (1973) Studies on natural odoriferous compounds VIII. Characteristic marking secretions of two forms lapponicus and scandinavicus of B. lapponicus Fabr. (Hymenoptera, Apidae). Chemica Scripta, 4, 231-239.

Bickford D., Lohman D.J., Sodhi N.S., Ng P.K.L., Meier R., Winker K., Ingram K.K., Das I. (2007) Cryptic species as a window on diversity and conservation. Trends Ecol. Evol. 22, 148-155.

Biella P., Bogliani G., Cornalba M., Manino A., Neumayer J., Porporato M., Rasmont P., Milanesi P. (2017) Distribution patterns of the cold adapted bumblebee Bombus alpinus in the Alps and hints of an uphill shift (Insecta: Hymenoptera: Apidae). J. Ins. Conserv. 21(2), 357-366.
Brasero N., Martinet B., Urbanová K., Valterová I., Torres A., Hoffmann W., Rasmont P., Lecocq T. (2015) First chemical analysis and characterization of the male species-specific cephalic labial gland secretions of South American bumblebee. Chem. Biodivers. 12 (10), 1535-1546.

Brasero N., Lecocq T., Martinet B., Valterová I., Urbanová K., de Jonghe R. (2017) Variability in Sexual Pheromones Questions their Role in Bumblebee Pre-Mating Recognition System. J. Chem. Ecol. https://doi. org/10.1007/s10886-017-0910-4.

Carolan J.C., Murray T.E., Fitzpatrick U., Crossley J., Schmidt H., Cederberg B., McNally L., Paxton R.J., Williams P.H., Brown M.J.F. (2012) Colour patterns do not diagnose species: quantitative evaluation of a DNA barcoded cryptic bumblebee complex. PLoS One, 7, e29251.

Claudet J., Pelletier D., Jouvenel J.Y., Bachet F., Galzin R. (2006) Assessing the effects of Marine Protected Area (MPA) on a reef fish assemblage in a northwestern Mediterranean marine reserve: identifying community-based indicators. Biol. Conserv. 130, 346-369.

Coppée A., Terzo M., Valterova I., Rasmont P. (2008) Intraspecific variation of the cephalic labial gland secretions in Bombus terrestris (L.) (Hymenoptera: Apidae). Chem. Biodivers. 5, 2654-2661.

Cruaud A., Gautier M., Galan M., Foucaud J., Sauné L., Genson G., Dubois E., Nidelet S., Deuve T. and Rasplus J.-Y. (2014) Empirical Assessment of RAD Sequencing for Interspecific Phylogeny. Mol. Biol. Evol. 31, 1272-1274.

Dellicour S., Lecocq T. (2013a) GCALIGNER 1.0 and GCKOVATS 1.0 - Manual of a Software Suite to Compute a Multiple Sample Comparison Data Matrix from Eco-chemical Datasets Obtained by Gas Chromatography. University of Mons, Mons.

Dellicour S., Lecocq T. (2013b) GCALIGNER 1.0: an alignment program to compute a multiple sample comparison data matrix from large eco-chemical datasets obtained by GC. J. Sep. Sci. 36, 3206-3209.

De Meulemeester T., Gerbaux P., Boulvin M., Coppee A., Rasmont P. (2011) A simplified protocol for bumble bee species identification by cephalic secretion analysis. Insectes Sociaux 58, 227-236.

De Queiroz K. (2007) Species concepts and species delimitation. Syst. Biol. 56, 879-886.

Dufrene M., Legendre P. (1997) Species assemblages and indicator species: The need for a flexible asymmetrical approach. Ecol. Monogr. 67, 345-366.

Engel M.S. (2011) Systematic melittology: where to from here? Syst. Entomol. 36, 2-15.

Eriksen B., Molau U., Svensson M. (2006) Reproductive strategies in two arctic Pedicularis species (Scrophulariaceae). Ecography, 16 (2), 154-166

Glaser N., Frérot B., Leppik E., Monsempes C., Capdevielle-Dulac C., Le Ru B., Lecocq T., Harry M., Jacquin-Joly E., Calatayud P.-A. J. (2014) Similar Differentiation Patterns Between PBP Expression 
Levels and Pheromone Component Ratios in Two Populations of Sesamia nonagrioides. Chem. Ecol. 40, 923-927.

Goulson D. ( 2010) Bumblebees : Behaviour Ecology, and Conservation. Oxford University Press, Oxford, 336 p.

Heinrich B. (2005) Bumblebee economics. Harvard University Press, Cambridge, London, England, 245p.

Hovorka O., Valterová I., Rasmont P., Terzo M. (2006) Male cephalic labial gland secretions of two bumblebee species of the subgenus Cullumanobombus (Hymenoptera: Apidae: Bombus Latreille) and their distribution in Central Europe. Chem. Biodivers. 3, 1015-1022.

Kevan P.G. (1973) Flowers, insects, and pollination ecology in the Canadian high Arctic. Polar Record, 16, 667674.

Klein A.M., Vaissière B.E., Cane J.H., Steffan-Dewenter I., Cunningham S.A., Kremen C., Tscharntke T. (2007) Importance of pollinators in changing landscapes for world crops. Proc. R. Soc. B Biol. Sci. 274, 303-313.

Kullenberg B., Bergstrøm G., Stallberg-Stenhagen S. (1970) Volatile Components of the Cephalic Marking Secretion of Male Bumble Bees. Acta Chem. Scand. 24, 1481 .

Lecocq T., Dellicour S., Michez D., Dehon M., Dewulf A., De Meulemeester T., Brasero N., Valterova I., Rasplus J.Y., Rasmont P. (2015) Methods for species delimitation in bumblebees (Hymenoptera, Apidae, Bombus ): towards an integrative approach. Zool. Scripta 44, 281-297.

Löfstedt C. (1993) Moth pheromone genetics and evolution. Philos. Trans. R. Soc. London Ser. B: Biol. Sci, $340,167-177$.

Løken A. (1973) Studies on Scandinavian bumble bees Hymenoptera, Apidae. Norsk Entomologisk Tidsskrift 20, 1-218.

Martinet B., Lecocq T., Smet J. and Rasmont P. (2015) A Protocol to Assess Insect Resistance to Heat Waves, Applied to Bumblebees (Bombus Latreille, 1802). PLoS ONE, 10(3), e0118591.

Martinet B., Lecocq T., Brasero N., Biella P., Urbanová K., Valterová I., Cornalba M., Gjershaug J.O., Michez D., Rasmont P. (2018) Following the Cold: Geographic Differentiation between Interglacial Refugia and Speciation in Arcto-Alpine Species Complex Bombus monticola (Hymenoptera: Apidae). Syst.Entomol. 43, 200-217.

Matoušková P., Luxová A., Matoušková J., Jiroš P., Svatoš A., Valterová I., Pichová I. (2008) A $\Delta 9$ desaturase from Bombus lucorum males: Investigation of biosynthetic pathway of marking pheromones. ChemBioChem, 9, 2534-2541.

Michener, C.D. (2007) The Bees of the World. Second Edition. Johns Hopkins University, Baltimore, 1016 pp.

Milliron H.E., Olivier D.R. (1966) Bumblebees from Northern Ellesmere Island, with observations on usurpations by Megabombus hyperboreus (Schönherr) (Hymenoptera: Apidae). Can. Entomol. 98, 207-213.
Milliron H.E. (1973) A monograph of the western hemisphere bumblebees (Hymenoptera: Apidae; Bombinae). II. The genus Megabombus subgenus Megabombus. Mem. Ent. Soc. Can. 89, 81-237.

Mutanen M., Kivelä S.M., Vos R.A., Doorenweerd C., Ratnasingham S., Hausmann A., Huemer P., Dincă V., van Nieukerken E.J., Lopez-Vaamonde C., Vila R., Aarvik L., Decaëns T., Efetov K.A., Hebert P.D., Johnsen A., Karsholt O., Pentinsaari M., Rougerie R., Segerer A., Tarmann G., Zahiri R., Godfray HC. (2016) Species-Level Para- and Polyphyly in DNA Barcode Gene Trees: Strong Operational Bias in European Lepidoptera. Syst. Biol. 65, 1025-1040.

Oksanen J., Blanchet F.G., Friendly M., Kindt R., Legendre P., McGlinn D., Minchin P.R., O'Hara R.B., Simpson G.L., Solymos P., Stevens M.H.H., Szoecs E., Wagner H. (2017) Tertiary Vegan: Community Ecology Package. https:/cran.r-project.org/web/packages/vegan/index.html. Accessed 5 Oct 2018.

Paradis E., Claude J., Strimmer K. (2004) APE: analyses of phylogenetics and evolution in $\mathrm{R}$ language. Bioinformatics, 20, 289-290.

Patiny S., Michez D., Rasmont P. (2009) A survey and review of the status of wild bees in the WestPalaearctic region. Apidologie, 40, 313-331.

Paterson H.E.H. (1993) Evolution and the Recognition Concept of Species. The Johns Hopkins University Press, Baltimore, Maryland.

Pekkarinen A., Teräs I., Viramo J., Paatela J. (1981) Distribution of bumblebees (Hymenoptera, Apidae: Bombus and Psithyrus ) in eastern Fennoscandia. Notulae Entomologicae 61, 71-89.

Potapov G.S., Kondalov A.V., Spitsyn V.M., Filippov B. Yu., Kolosova Yu S., Zubrii N.A., Bolotov I.N. (2018) An integrative taxonomic approach confirms the valid status of Bombus glacialis, an endemic bumblebee species of the High Arctic. Polar Biology, 41 : 629-642.

Rasmont P., Franzen M., Lecocq T., Harpke A., Roberts S.P.M., Biesmeijer K., Castro L., Cederberg B., Dvorak L., Fitzpatrick U., Gonseth Y., Haubruge E., Mahé G., Manino A., Michez D., Neumayer J., Odegaard F., Paukkunen J., Pawlikowski T., Potts S.G., Reemer M., Settele J., Straka J. and Schweiger O. (2015) Climatic risk and distribution atlas of European bumblebees. BioRisk, 10, 1-236.

R Development Core Team. (2017) R: A Language and Environment for Statistical Computing. R Foundation for Statistical Computing, Vienna. [WWW document]. URL http://www.R-project.org/ [accessed on 17 October 2017].

Richards O.W. (1931) Some notes on the humble-bees allied to Bombus alpinus, L. Tromsø Museums Årshefter, 50, 1-32.

Richards K.W. (1973) Biology of Bombus polaris Curtis and B. hyperboreus Schönherr at lake Hazen, northwest territories (Hymenoptera: Bombini). Quaestiones entomologicae 9, 115-57.

Roelofs W.L., Liu W., Hao G., Jiao H., Rooney A.P., Linn Jr. C.E. (2002) Evolution of moth sex pheromones via ancestral genes. Proc. Natl. Acad. Sci. U.S.A. 99, 13621-13626. 
Schlick-Steiner B.C., Steiner F.M., Seifert B., Stauffer C., Christian E., Crozier R.H. (2010) Integrative taxonomy: a multisource approach to exploring biodiversity. Annu. Rev. Entomol. 55 , 421-438.

Shamurin V.F. (1966) Rol' nasekomikh-opilitelei V tundrovikh soobshchestvakh. [The role of insects in tundra communities]. Organizmi iprirodnayasreda. Voprosi geographii

Skorikov AS. (1914) Les formes nouvelles des bourdons (Hymenoptera, Bombidae). VI. Russkoe éntomologicheskoe Obozrênie 14, 119-129.

Soltani G.G., Bénon D., Alvarez N., Praz J.C. (2017) When different contact zones tell different stories: putative ring species in the Megachile concinna species complex (Hymenoptera: Megachilidae). Biol. J. Linn. Soc. 121(4), 815-832.

Suzuki R., Shimodaira H. (2011) Pvclust: Hierarchical Clustering with P-values via Multiscale Bootstrap Resampling. Contributed package. Version 1-1.10. R Foundation for Statistical Computing, Vienna. [WWW document]. URL http://www.R-project.org [accessed on 17 October 2017].

Stenström M., Bergman P. (1998). Bumblebees at an alpine site in northern Sweden: temporal development, population size, and plant utilization. Ecography 21(3), 306-316.

Svensson B.G. (1980) Species-isolating mechanisms in male bumblebees (Hymenoptera, Apidae). Acta Universitatis Upsaliensis 549, 1-42.

Svensson B.G., Bergström G. (1979) Marking pheromones of Alpinobombus males. J. Chem. Ecol. 5, 603-615.

Svensson B.G., Appelgren M., Bergstrom G. (1984) Geranylgeranyl acetate and 2 heptadecanone as the dominant marking secretion components of the labial glands in the bumblebee Alpigenobombus wurfleini Nov. Acta Regiae Soc. Sci. 3, 145-148.

Symonds M. R. E. and Elgar M. A. (2004) The mode of pheromone evolution: evidence from bark beetles. Proc. R. Soc. Lond. B. 271, 839-846.

Symonds M. R. E. and Elgar M. A. (2007) The evolution of pheromone diversity. Trends Ecol. Evol. 23 , 220-228.

Symonds M.R.E., Moussalli A., Elagar M.A. (2009) The evolution of sex pheromones in an ecologically diverse genus of flies. Biol J Linn Soc 9, 594-603.

Taylor K., Rumsey F.J. (2003). Bartsia alpina L. J. Ecol. 91(5), 908-921.

Terzo M., Urbanova K., Valterova I., Rasmont P. (2005). Intra and interspecific variability of the cephalic labial glands' secretions in male bumblebees: the case of Bombus (Thoracobombus) ruderarius and $B$. (Thoracobombus) sylvarum Hymenoptera, Apidae. Apidologie, 36, 85-96.

Trunz V., Packer L., Vieu J., Arrigo N., Praz C.J. (2016) Comprehensive phylogeny, biogeography and new classification of the diverse bee tribe Megachilini: Can we use DNA barcodes in phylogenies of large genera? Mol. Phylogenetics Evol. 103, 245-259.

Vincenti M., Guglielmetti G., Cassani G., Tonini C. (1987) Determination of Double Bond Position in Diunsaturated Compounds by Mass Spectrometry of Dimethyl Disulfide Derivatives. Anal. Chem. 59, 694-699.

Williams P.H., Cameron S.A., Hines H.M., Cederberg B., Rasmont P. (2008) A simplified subgeneric classification of the bumblebees (genus Bombus). Apidologie, 39, 46-74.

Williams P.H., Brown M.J.F., Carolan J.C., An J., Goulson D., Aytekin A.M., Best L.R., Byvaltsev A.M., Cederberg B., Dawson R., Huang J., Ito M., Monfared A., Raina R.H., Schmid-Hempel P., Sheffield C.S., Sima P., Xie Z. (2012) Unveiling cryptic species of the bumblebee subgenus Bombus s. str. worldwide with COI barcodes (Hymenoptera: Apidae). Syst. Biodivers. 10(1), 21-56.

Williams P.H., Byvaltsev A.M., Cederberg B., Berezin M.V., Ødegaard F., Rasmussen C., Richardson L.L., Huang J., Sheffield C.S., Williams S.T. (2015) Genes suggest ancestral colour polymorphisms are shared across morphologically cryptic species in arctic bumblebees. PLoS One, 10(2), e0144544.

Williams P.H., Cannings S.G., Sheffield C.S. (2016) Cryptic subarctic diversity: a new bumblebee species from the Yukon and Alaska (Hymenoptera: Apidae). J. Nat. Hist. 50 (45-46), 2881-2893.

Wyatt T.D. (2003) Pheromones and animal behaviour: communication by smell and taste. Cambridge University Press, Cambridge.

Žacek P., Prchalova-Hornakova D., Tykva R., Kindl J., Vogel H., Svatoš A., Pichová I., Valterová I. (2013) De novo biosynthesis of sexual pheromone in the labial gland of bumblebee males. ChemBioChem, 14, 361-371.

Žáček P., Kalinová B., Šobotník J., Hovorka O., Ptácek V., Coppée A., Verheggen F., Valterová I. (2009) Comparison of age-dependent quantitative changes in the male labial gland secretion of Bombus terrestris and Bombus lucorum. J. Chem. Ecol. 35, 698-705. 